\title{
Coerced regimes: management challenges in the Anthropocene
}

\author{
$\underline{\text { David G. Angeler }}^{1,2}, \underline{\text { Brian C. Chaffin }}^{3}$, $\underline{\text { Shana M. Sundstrom }}^{2}, \underline{\text { Ahjond Garmestani }}^{4,5}, \underline{\text { Kevin L. Pope }}^{6} \underline{\text { Daniel R. Uden }}^{2}, \underline{\text { Dirac }}^{7,8}$ \\ Twidwell $^{7,8}$ and Craig R. Allen ${ }^{2,8}$
}

\begin{abstract}
Management frequently creates system conditions that poorly mimic the conditions of a desirable self-organizing regime. Such management is ubiquitous across complex systems of people and nature and will likely intensify as these systems face rapid change. However, it is highly uncertain whether the costs (unintended consequences, including negative side effects) of management but also social dynamics can eventually outweigh benefits in the long term. We introduce the term "coerced regime" to conceptualize this management form and tie it into resilience theory. The concept encompasses proactive and reactive management to maintain desirable and mitigate undesirable regime conditions, respectively. A coerced regime can be quantified through a measure of the amount of management required to artificially maintain its desirable conditions. Coerced regimes comprise "ghosts" of self-sustaining desirable system regimes but ultimately become "dead regimes walking" when these regimes collapse as soon as management is discontinued. We demonstrate the broad application of coerced regimes using distinct complex systems of humans and nature (human subjects, aquatic and terrestrial environments, agriculture, and global climate). We discuss commonalities and differences between these examples to identify trade-offs between benefits and harms of management. The concept of coerced regimes can spur thinking and inform management about the duality of what we know and can envision versus what we do not know and therefore cannot envision: a pervasive sustainability conundrum as planet Earth swiftly moves toward a future without historical analogue.
\end{abstract}

Key Words: alternative regimes; coercion; interdisciplinary; management; mitigation; resilience; restoration

\section{INTRODUCTION}

That the dynamics of systems of people and nature are highly complex and uncertain is a well-established scientific axiom(Allen et al. 2014). This complexity and uncertainty stems partly from the interaction of distinct processes, including adaptation, recalibration, and self-organization (Holland 2014). Inherent in these dynamics is the potential for complex systems to exist in alternative, often stable regimes, each with fundamentally different structures, functions, processes, and feedbacks (Holling 1973, Scheffer et al. 1993, Beisner et al. 2003). Alternative regimes are ubiquitous and occur, for instance, in cells (Ferrell 2002), human subjects (Angeler et al. 2018), and geopolitical, ecological, social, social-ecological, climatic, and economic systems (Miller and Williamson 1988, Biggs et al. 2018, Steffen et al. 2018). Examples include clear-water lakes rapidly becoming turbid, the social-ecological system organized around Atlantic cod Gadus morhua changing to an American lobster Homarus americanus fishery, healthy human subjects becoming mentally ill, and the current rapid change exhibited in our global climatic regime.

Regime shifts are frequently undesired because the alternative regimes, once stabilized in a new attractor domain, are often permanently degraded and uncertain in the sense that they provide humanity fewer and often unreliable benefits. There is thus a fundamental need to transform degraded systems regimes to ideally self-perpetuating regimes that guarantee the provisioning of ecosystem goods and services, i.e., "desirable regimes." There is also need to maintain the adaptive capacity of desirable regimes and avoid exceeding critical thresholds (regime shift) that may lead to a regime that can be deleterious for human health and security (Angeler et al. 2019). The pressing need to harness desirable system functioning for human welfare leads to an increased examination of alternative system regimes and their management through the lens of resilience theory (Angeler et al. 2016). Novel concepts are emerging that add to well-established terms used in the ecological restoration (Table 1) and resilience literature (Angeler and Allen 2016). Coerced resilience, for instance, is a term that has been introduced to focus on the resilience of production ecosystems (aquaculture, forestry, agroecosystems; Rist et al. 2014). It refers to enabling and maintaining high levels of production of a system as a result of external anthropogenic inputs, which in the long term may lead to the erosion of the resilience of the system. Coercing the resilience of systems over long periods is costly and can cause the system to shift into a less desired alternative regime (Gunderson 2000). Similarly, when a system has undergone a regime shift, the new, undesired regime may require constant and considerable management to mimic the desired previous regime (Angeler et al. 2018).

The term "coerced resilience" has been used from two mechanistically different perspectives: improving and mimicking desired regimes. We consider coerced resilience in a broader context, accounting for reactive and proactive management aimed at the deliberate creation of artificial regime conditions to guarantee social-ecological sustainability. We characterize the term "coerced regimes" as a management form that fails to achieve self-organization and therefore requires constant management for maintaining and creating desirable system regimes. We envision that management is likely to intensify in the near future to satisfy the needs for ecosystem goods and services of a growing human population in a fast changing Anthropocene. There is high

${ }^{1}$ Swedish University of Agricultural Sciences, Dept. of Aquatic Sciences and Assessment, ${ }^{2}$ School of Natural Resources, University of NebraskaLincoln, ${ }^{3}$ W.A. Franke College of Forestry and Conservation, University of Montana, ${ }^{4}$ U.S. Environmental Protection Agency, ${ }^{5}$ Utrecht Centre for Water, Oceans and Sustainability Law - Utrecht University School of Law, ${ }^{6}$ U.S. Geological Survey - Nebraska Cooperative Fish and Wildlife Research Unit, ${ }^{7}$ Department of Agronomy and Horticulture, University of Nebraska-Lincoln, ${ }^{8}$ Center for Resilience in Agricultural Working Landscapes, University of Nebraska-Lincoln 
Table 1. Definitions of coercion terms that are used across different scientific fields.

\begin{tabular}{|c|c|}
\hline Term & Definition \\
\hline Restoration & $\begin{array}{l}\text { The intentional activity that initiates or accelerates the recovery of an ecosystem with respect to its health, } \\
\text { integrity, and sustainability (SER 2004). }\end{array}$ \\
\hline Rehabilitation & $\begin{array}{l}\text { The repair and replacement of essential structures and functions to achieve specified objectives without the } \\
\text { pretense of accomplishing absolute authenticity of predisturbance conditions (Cooke 1999). }\end{array}$ \\
\hline Mitigation & Intended to offset known impacts to an existing historic or natural resource. \\
\hline Coerced resilience & $\begin{array}{l}\text { Resilience that is created as a result of anthropogenic inputs, such as labor, energy, and technology, rather } \\
\text { than supplied by the ecological system itself, whereby coercion of resilience enables the maintenance of } \\
\text { high levels of production (Rist et al. 2014). Coerced resilience can be considered to focus on improving the } \\
\text { performance of a single or few system variable(s), e.g., production output. }\end{array}$ \\
\hline Coerced regimes & $\begin{array}{l}\text { Focuses on the creation of artificial, nonself-sustaining feedbacks through constant management to mimic } \\
\text { the conditions of a desirable regime (this paper). Coerced regimes can also arise from unintentional social } \\
\text { dynamics (see text). The concept is inclusive of proactive (maintaining desired) and reactive (mitigating } \\
\text { degraded regimes) management. Contrary to coerced resilience, coerced regimes focuses on mimicking of } \\
\text { systemic conditions (feedbacks), rather than the optimization of a few system variables. Coerced regimes } \\
\text { are "dead regimes walking" manifested in the collapse of coerced desired system regimes and the return of } \\
\text { a coerced degraded regime to the full manifestation of its undesired conditions when management is } \\
\text { ceased. }\end{array}$ \\
\hline Forced resilience $^{\dagger}$ & In a psychological context, refers to a willful coping with trauma and adversity (Handy 2018). \\
\hline Command-and-control management & $\begin{array}{l}\text { Pathological management that decreases the resilience and adaptive capacity of a system through } \\
\text { controlling a particular ecosystem regime indefinitely into the future (Holling and Meffe 1996). Coerced } \\
\text { resilience management often comprises a form of command and control management }\end{array}$ \\
\hline Social coercion & $\begin{array}{l}\text { The practice of forcing another party to act in an involuntary manner by use of threats or force (Anderson } \\
\text { 2017). }\end{array}$ \\
\hline Poverty/rigidity traps & $\begin{array}{l}\text { With its focus on reactive management to mitigate highly degraded and resilient social-ecological system } \\
\text { regimes, this concept is subsumed within the concept of coerced regimes. }\end{array}$ \\
\hline $\begin{array}{l}\text { Coercivity (in material science } \\
\text { and electrical engineering) }\end{array}$ & $\begin{array}{l}\text { A measure of the ability of a ferromagnetic material to withstand an external magnetic field without } \\
\text { becoming demagnetized (Wandelt 2018). }\end{array}$ \\
\hline
\end{tabular}

uncertainty regarding costs (unintended consequences, including negative side effects) of management that may outweigh benefits in the long term. It is also uncertain how social dynamics lead to unintended coerced regimes. This new concept therefore motivates discussions about what we know and envision versus what we do not know and therefore cannot envision, a conundrum that pervasively plagues management toward sustainability. We discuss these issues using social-ecological systems and other complex systems (human brain) to demonstrate the broad application of this term and examine them for commonalities and differences.

\section{DEFINITION}

We distinguish coerced regimes from related concepts (Table 1) and resilience terms (Angeler and Allen 2016) and define it as follows: creating nonself-organizing system regimes that sustain human needs and well-being through constant management (Fig. 1). Inherent in the definition of coerced regimes is that management does not break the feedbacks that stabilize a system regime, a notion well aligned with ecological restoration theory (Suding et al. 2004, Suding and Gross 2006). Coerced regimes are therefore untenable without management; they only comprise the "ghosts" of desirable self-organizing regimes, and therefore essentially become "dead regimes walking" that collapse once management is discontinued.

The concept of coerced regimes offers a broad management perspective across a wide array of complex system types. The terminology borrows from the social sciences, where coercion is defined as the inverse of freedom (Twidwell et al. 2019). Coercion
Fig. 1. Illustration of coerced resilience. Shown are changes over time (blue arrow) of a desired (green) and undesired (red) regime. The shifting shapes of basins of attraction show that the desired regime becomes increasingly untenable while the undesired regime more stable over time. Increasing management intervention (purple arrows) are needed to coerce the system (symbolized with ball) into the ghost of a desired regime past (gray area warping the no longer existent basin of attraction and steep slopes leading into the undesired basin of attraction)

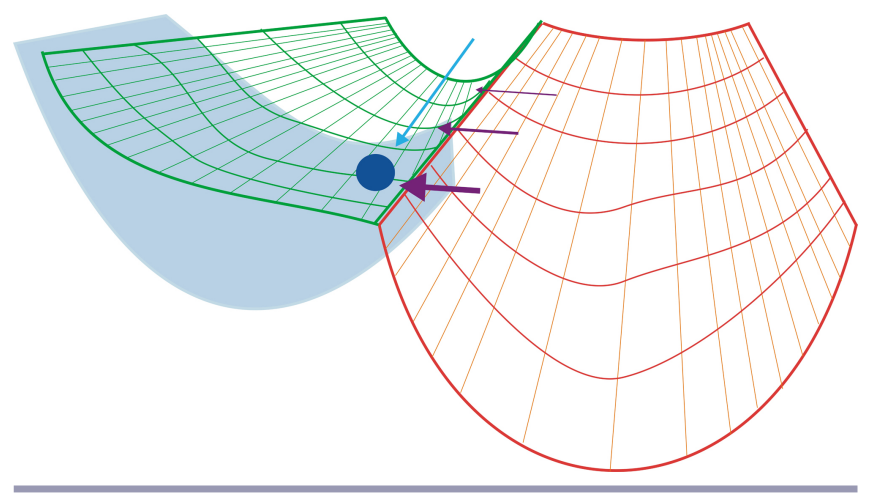

entails reciprocity in the forceful persuasion among actors to achieve goals. These goals may not only be influenced by intended but also unintended human agency that might have indirect effects resulting from social dynamics or power relations. We therefore 
think coercion is a useful analogy in the specific context of management of complex systems of people and nature. First, defining the goals of human management of social-ecological or other types of complex systems requires the use of persuasion because the definition of management endpoints and their societal relevance is subjective and varies between actors in a social-ecological system (e.g., Blythe et al. 2018). Humans need to persuade other humans to generate shared management objectives. Second, the use of coercion terminology provides a mechanistic basis for discussions of the different forms of regime management. For example, regime management can be aimed at maintaining a system in a desired regime, which has very different implications than the goal of mimicking the conditions of a desirable regime. In the first instance, a social-ecological system is already in a regime that is deemed beneficial and desirable to the humans investing in it, and management efforts would focus on supporting or even increasing the resilience of the key processes and feedbacks maintaining the system in that regime. For example, nutrient inputs into a shallow freshwater lake would be kept low so as to not risk the possibility of a regime shift to eutrophic conditions. In the second instance, a social-ecological system is only being held in a particular regime by constant human inputs that are critically necessary to maintain feedbacks, such as the regular liming of lakes to maintain their $\mathrm{pH}$. Using the term coercion has value because it focuses on the long-term viability of management in a nonstationary world, thereby embracing the uncertainty surrounding the trade-offs between costs and benefits that management and other forms of agency, e.g., social dynamics, may entail.

The viability and trade-offs of different management choices also relate to operational aspects of management that are relevant from a quantification point of view, which further underscores the usefulness of the analogous use of coercion terminology. That is, a coerced regime can be quantified through a measure of the amount of management required to maintain its desired conditions. This directly relates to the ecological resilience of a system because the more human inputs required to maintain ecological feedbacks and the key processes and functions associated with a particular regime, the less resilient a system will be (Gunderson 2000). Furthermore, managers often choose management goals that are focused on maintaining specific resilience, such as a certain harvest rate of a product such as a fishery, agricultural crop, or timber, or to increase the resilience of an ecological service such as flood control. These management goals are designed to reduce variability (Holling and Meffe 1996) but in practice reduce overall system resilience, by simplifying abiotic and biotic structures.

Management often aims to transform regimes from degraded to less degraded, or even to desirable regimes that are selfmaintaining and self-perpetuating. When management fails to restore, and therefore only mimics, the conditions and functionality of a past or novel, self-organizing, desired regime it only manages for the "ghost of a (past) desired regime." Management also often aims at conserving desirable system regimes that are no longer viable and that would switch to an alternative, frequently undesired regime if management were discontinued. Such conservation may not be indefinitely possible in a rapidly changing world. A related form of management relates to human-made artificial systems, e.g., production ecosystems such as agriculture, that need constant management and subsidies to maintain desirable system conditions with enhanced production. As soon as the management of such systems is discontinued they tend to drift toward previously existing natural ecosystems, e.g., succession towards forest (Gill and Marks 1991). The coerced regime features of production systems and potentially other complex systems without a natural analogue are also inherent in the definition of coerced resilience (Rist et al. 2014); that is, management creates an artificial regime and targets enhanced production within it. This indicates that the concept of coerced regimes is also inclusive of coerced resilience (Table 1).

Coerced regimes are ubiquitous across complex systems and range, for instance, from the use of performance-enhancing drugs in athletes, to the mitigation of poverty traps, to sustainable cities and political systems. We discuss in detail several transdisciplinary examples of coerced regimes that align with our definition and demonstrate general applicability across distinct scientific disciplines and systems of people and nature. We present examples that demonstrate the unrecognized prevalence of coerced regimes, and organize them by the scale (from human individuals to the global climate). Our examples focus on the maintenance and mimicking of desirable conditions, but we acknowledge that regime coercion can be undesirable, for example, in alcoholism or drug abuse where humans self-coerce their emotional and physical state.

\section{EXAMPLES OF COERCED REGIMES}

\section{Diseased regimes of human subjects}

Bipolar or manic-depressive disorder is an affective disorder with pronounced mood swings that manifest once a human subject has shifted from a healthy to the diseased regime (Angeler et al. 2018). These mood swings comprise recurrent cycles of (hypo)mania symptoms (increased energy levels, decreased need for sleep, racing thoughts, pressure of speech, frequent agitation, confusion and distraction, heightened libido, and in extreme forms hallucinations and delusions) and severe depression episodes (chaos, emotional emptiness, despair, self-stigma, doom, anhedonia, guilt, monochromatic world view, and suicidal ideology; Goodwin and Jamison 2007). The disorder comprises a spectrum wherein (hypo)manic and depression symptoms manifest with high variability and magnitude among patients, and these symptoms often co-occur (mixed states; Phelps 2006). The illness affects between 3 to $8 \%$ of the human population (Goodwin and Jamison 2007), although this percentage may be higher because current diagnostic problems complicate differentiating between unipolar and bipolar depression (Bauer and Pfennig 2005)

As is the case with other mental illnesses, bipolar disorder is managed to mitigate symptoms and improve the patient's personal and interpersonal functioning. From a coerced-regimes perspective, this management treats the diseased regime through psychopharmacological treatment, therapy, mindfulness, and exercise to approximate conditions of a healthy regime (Phelps 2006). That the diseased condition of the disorder is a coerced regime is manifested in a return of full-blown symptoms of (hypo) mania and depression once clinical treatment is discontinued (Milkowitz and Gitlin 2015). This is because the disorder is chronic and has no cure, which highlights that the diseased regime 
comprises a stable alternative regime from which a return to the healthy regime is impossible. Thus, the goal of treatment of the disorder is to manage for the "ghost of a healthy-regime past." Treatment of bipolar disorder also exemplifies negative side effects that may counteract the management efficiency, for instance, medication toxicity, medication to control side-effects of other medicaments, weight changes, sedation, cardiovascular problems, and other physical diseases (Correll et al. 2015, Milkowitz and Gitlin 2015).

\section{Restoring and mitigating degraded ecosystems}

Anthropogenic acidification of surface waters has been a major environmental problem in northern Europe and eastern North America during the epoch of flourishing industrial activity. Acid rain impacted aquatic ecosystems by lowering $\mathrm{pH}$ and increasing aluminum concentrations beyond lethal thresholds for organisms, leading to a loss of biodiversity and profound alteration of community structure and ecosystem processes (Schindler 1988). This led in many cases to a shift from a circumneutral regime to an acidified regime (Baho et al. 2014). To counteract acidification effects and mimic conditions of a circumneutral regime, countries in Europe and North America implemented large-scale mitigation programs based on application of crushed limestone (liming) to surface waters and catchments (Henriksson and Brodin 1995, Sandøy and Romunstad 1995).

It is increasingly recognized that liming, rather than restoring circumneutral regimes, only mitigates acidification effects, thereby managing the acidified regime to approximate lake conditions that are conducive to ecosystem service provisioning, e.g., recreational and commercial fishing and aquaculture. As is the case with the bipolar example, liming manages for the "ghost of a past circumneutral lake regime." Limed conditions ultimately return to acidic conditions once management is discontinued (Clair and Hindar 2005). In conservation ecology, liming has been regarded as pathological because of its profound alteration of biogeochemical and biological variables (Angeler et al. 2017), which provides another example of negative side-effects of management in coerced regimes.

\section{Maintaining desired regimes in a sea of change}

A universal threat despite the inherent geographic and evolutionary isolation of grasslands is woody encroachment (Briggs et al. 2005). In the Great Plains of North America, many grassland ecosystems are threatened by encroachment of Eastern red cedar Juniperus virginiana (Roberts et al. 2019). This species was formerly rare because of its extreme sensitivity to fire. However, since the influx of agrarian colonists into the U.S. Great Plains in the 1850 s, fire was largely suppressed, disrupting the natural disturbance regime in which fire played an essential role (DellaSala and Hanson 2015). This has facilitated the incursion of Eastern red cedar and other woody species into the Great Plains and is driving a biome level regime shift (Roberts et al. 2019). The leading edge of the woody regime has been moving steadily north over the past 50 years, and has moved from southern Kansas in 1966 to southern Nebraska in 2016 (Roberts et al. 2019). This slow-moving (relative to human life-spans) but spatially extensive shift from grassland to woody shrubland has serious implications for humans and nature.

Grasslands and grassland biota are highly endangered in North America (Samson and Knopf 1994, Grant et. al. 2004), and in the United States several grassland species are threatened to an extent that they are listed under the Endangered Species Act (ESA). Birds such as the Greater Prairie-Chicken (Tympanuchus cupido) and Henslow's Sparrow (Centronyx henslowii) require management under the ESA, and the best management practice for these species is to maintain grassland habitat. This is difficult in a sea of cedar, where propagule pressure from the surrounding undesired (woody) regime is constant, which makes the establishment of trees in the grasslands highly successful (Cassey et al. 2018). Complicating matters, many North American grasslands are now highly fragmented such that spatially contagious processes, including fire, are excluded, unless purposely introduced (Fuhlendorf et al. 2018). The answer for remaining grassland patches isolated by the spread of the woody cedar regime is intensive management of patches through prescribed fire and a number of actions captured under the phrase "brush management" (e.g., Archer and Predick 2014). These approaches have been successful in maintaining patches of grassland, but these are increasingly isolated and vulnerable to fragmentation effects. Cessation of intensive management would lead to a rapid change of these remnant grassland patches to shrublands because of the extreme propagule pressure of the surrounding landscape. This highlights that much current grasslands management creates a ghost regime that is no longer viable.

\section{Artificial, beneficial regimes: agricultural production}

Many forms of agriculture, e.g., intensive-irrigated agriculture, are novel, human-managed regimes entirely geared toward the creation of benefits for humanity, i.e., the production of food (Rist et al.2014). Irrigated agriculture as a strongly coerced system is manifested in crop production in dryland areas of the world. For example, across Arizona, an area with low precipitation and natural surface water availability, 485,000 ha are under irrigated production, including an estimated 64,000 ha of cotton Gossypium spp., an extremely water-intensive crop relative to other crops grown in arid climates (Lustgarten and Sadasivam 2015). In the early to mid-20th century, groundwater was used exclusively to grow larger fields of cotton in this region, servicing a high-domestic demand during both World Wars, but as aquifers declined and pumping costs increased, the state of Arizona prevailed in its almost century-long battle to channel water from the Colorado River hundreds of kilometers to irrigate agricultural fields (including cotton) in central Arizona. Today, most cotton farmers irrigate with a mix of groundwater, Colorado River water, and surface water from other federal and state reclamation projects in Arizona.

The coerced nature of a cotton-farming regime in the deserts of Arizona is evident in that the market price of cotton no longer consistently supports the inputs (water pumping costs, fuel, fertilizer, pesticides, and labor) necessary to maintain its production. As well, the opportunity cost or willingness of others to pay for Colorado River water currently used to support cotton agriculture is rapidly rising because of the needs of more highvalue crops in downstream reaches of the basin and increasing municipal demands for water from cities such as Phoenix. The U. $\mathrm{S}$. and state governments have and continue to facilitate and incentivize cotton farming in Arizona through direct subsidies to farmers, low- or no-interest farm loans, and subsidized water delivery both directly and indirectly through massive 
Table 2. Comparison of coerced-resilience examples.

\begin{tabular}{|c|c|c|c|c|c|}
\hline System & Management & Goal & Spatial connectivity & Disturbance regime & Subsidy \\
\hline Bipolar & Restoration & $\begin{array}{l}\text { Cognitive and (inter)personal } \\
\text { functioning }\end{array}$ & No & Artificial & Chemical \\
\hline Lakes & Restoration & $\begin{array}{l}\text { Emblematic species } \\
\text { conservation; fisheries }\end{array}$ & Low & Artificial & Chemical \\
\hline Agriculture & Novelty & Food provisioning & High & Artificial & $\begin{array}{l}\text { Physical, chemical, } \\
\text { technological }\end{array}$ \\
\hline Grasslands & Maintenance & $\begin{array}{l}\text { Emblematic species and } \\
\text { rangeland conservation }\end{array}$ & High & Natural & Physical \\
\hline Climate & Maintenance & $\begin{array}{l}\text { Conserving planetary Glacial- } \\
\text { Interglacial climate regime }\end{array}$ & High & Natural, artificial & $\begin{array}{l}\text { Physical, technological, } \\
\text { social, political }\end{array}$ \\
\hline
\end{tabular}

infrastructure projects (Lustgarten and Sadasivam 2015). Without massive irrigation infrastructure, subsidized costs of moving water over hundreds of kilometers, and consistent yearly incentives to farmers, industrial cotton farming, and the subsequent greening of the surrounding ecosystem would likely cease in arid central Arizona. This indicates the lack of a selfsustaining regime in this type of coerced system, which is further supported by the initiation of successional dynamics toward natural ecosystem regimes, e.g., old field succession (Gill and Marks 1991), once elements of agriculture have been eliminated. Intensive agriculture also highlights substantial negative effects that arise from management, e.g., the use of nutrients and pesticides that impact the natural environment (Goudie 2018). This example is typical of other water-intensive cropping systems that are expanding globally and may pose significant sustainability challenges.

\section{Global climate regimes}

Substantial modeling evidence suggests profound future alterations in the world's climate with dramatic consequences for climatic system features such as temperature, polar ice-sheet coverage, marine jet streams, and sea-level rise as a result of human burning of fossil fuels (IPCC 2014). Changes to these features are expected to occur abruptly and nonlinearly, key characteristics of regime shifts. That such abrupt, substantial, and persistent changes in climatic systems, driven by temperature increase, are already taking place is supported by empirical observations. Evidence includes, for example, regime shifts in arctic marine environments (Kortsch et al. 2012) and other ocean regions in the Northern Hemisphere (Beaugrand et al. 2015), ground-water systems (Figura et al. 2011), and forest-fire regimes (Westerling et al. 2006).

Steffen et al. (2018) describe our current climate regime as a glacial-interglacial limit cycle, with an $\sim 100,000$-year cycle, selforganized and maintained during the past 1.2 million years. An alternative regime, which we have perhaps already entered, is called "Hothouse Earth," and uncertainty regarding Earth's trajectory within this regime suggests varying degrees of risk for sustaining human life should the Earth system move fully onto this attractor. Steffen et al. (2018) argue that we need to consider deliberately coercing the Earth system close to the threshold between the Glacial-Interglacial regime and Hothouse Earth. Maintaining the Earth system artificially in this GlacialInterglacial regime would require massive external subsidization by humans, as such a state would not be self-organizing. A series of measures, including decarbonization of the global economy, enhancement of biosphere carbon sinks, behavioral changes, technological innovations, new governance arrangements, and transformed social values have been identified as the minimal, but perhaps not sufficient, changes necessary to manage the Earth system away from the Hothouse Earth attractor. The objective would be to prevent the Earth system from moving fully into a potentially catastrophic Hothouse Earth regime by holding it in a coerced regime. Managing for the "ghost of the GlacialInterglacial climate" might buy humans time to eventually move the Earth system back onto the Glacial-Interglacial attractor. This example highlights the context dependence of the concept. The desirability of human management to prevent the Earth system from moving onto the Hothouse attractor is clearly more desirable than the alternative.

\section{COERCED REGIMES: COMMONALITIES AND \\ DIFFERENCES}

Our examples, which cover a range of hierarchical organization and complex-system types (from human subjects to the Earth's climate), represent applications of the concept of coerced regimes across a wide spectrum of systems of people and nature and scientific disciplines. All examples share the commonality of being untenable without constant management. Inspired by Helen Prejean's 1993 novel Dead Man Walking, we refer to a coerced regime as a "dead regime walking." Despite this common characteristic, our examples differ in several aspects (Table 2). These aspects relate to management forms, focus and goals, the imitation of disturbance regimes and systems dynamics, and the systems' connectivity with other systems.

Our examples represent two categories of management goals and focus: managing for maintenance, and managing for restoration. The first category, managing for maintenance, is exemplified by grasslands and targets the conservation of emblematic wildlife and rangelands for grazing. Without management these commodities would be threatened by cedar encroachment, a process that has become the main driver of an alternative, rapidly expanding woodland regime (Briggs et al. 2005). That is, management for maintenance of a grassland regime is designed to keep these systems from crossing a threshold leading to the cedar regime. In this case, management maintains a grassland ghost regime, which is no longer viable without human intervention. This type of management also occurs in novel, highly artificial systems such as irrigated agriculture that have no natural system regime analogue. Managing for maintenance is 
also evident in the implementation of Earth stewardship measures to maintain a safe operating space for humanity that is bound to the current Glacial-Interglacial climate regime (Rockström et al. 2009, Carpenter et al. 2017, Steffen et al. 2018). Despite being appealing, the effectiveness of Earth stewardship measures for preventing the Earth system from moving from the GlacialInterglacial attractor onto the Hothouse Earth attractor is uncertain given the connectedness and cross-scale complexity of combined ecological, economic, and social systems on our planet (Holling 2001). Given this uncertainty it is unclear how effective management of a current but no longer viable and self-sustaining climate regime can be. The climate example also makes clear that management for maintaining the climate regime involves radically different forms of human interventions (Earth stewardship measures) compared to those that have contributed to its deterioration (unsustainable use of fossil fuels). The climate example highlights that hysteresis can impose limitations on the efficacy of regime management, a fact well known in restoration ecology (Suding and Hobbs 2009), requiring different, more complex and likely costlier approaches to keep the dead regime walking. The second category, managing for restoration, is evident in the bipolar and acidification examples. Contrary to the grassland and climate cases, these examples show that management is designed to mitigate the impact of undesired regimes and approximate conditions of a previous desired regime. That is, management focuses on the ghost of a desired regime past. Also in these cases, coerced regimes arise from our inability to overcome hysteresis, which would be prerequisite for reincarnating the ghost as a self-organizing regime. In other words, we are incapable of moving the system back to its original configuration because the original conditions permitting the previous regime are no longer an option, either from lack of knowledge regarding feedbacks and mechanisms regulating the original regime, or because the basic prerequisites for a specific system configuration, i.e., local and regional environmental conditions, no longer exist, or both.

It follows from our examples that coerced regimes vary in the types, quantities, frequencies, and consequences of management they require. Our example systems therefore are coerced in terms of their degree and form of management. Coercion, like resilience, is not inherently good or bad; it depends entirely on context and human perception. In a time of increasing nonstationarity across many kinds of human and ecological complex adaptive systems, climate change alone demands that we make fully informed choices about when and where we intervene in systems and what degree of management will be likely to achieve our desired goals. Ecological and social-ecological systems will be at increasing risk of being dead regimes walking as the underlying environmental conditions allowing them to operate in their current regime change. Humankinds' wish to manage for a desired system regime does not mean we have the ability to do so. In particular, managing for desired regimes that are resilient and self-reinforcing may be beyond our means because of lack of data, lack of resources, and a lack of control over all the variables that impact ecosystems. When systems lack self-organization, the next best option may be to coerce desirable conditions in a system that would otherwise move into a different basin of attraction governed by a different regime, though even this management goal will necessarily be constrained by the availability of labor, time, and money. It may be highly useful to evaluate potential system interventions from the perspective of evaluating the type and quantity of management required, i.e., are they ecologically and economically sustainable; the frequency required; and the consequences generated, such as wastes, vulnerabilities induced, and potential knock-on effects of management, in order to explicitly understand the trade-offs at stake. For example, intensive agriculture versus agroecological farming systems differ in their impacts on soil, biodiversity, the delivery of ecosystem goods and services, pollution of aquatic systems, and their resilience to system disruption (Gordon et al. 2008, Koohafkan et al. 2012, Altieri et al. 2015, Garibaldi et al. 2017). It also seems likely that more intensive management over larger spatial and temporal scales runs the risk of generating more unintended consequences, e.g., homogenization and variance reduction (e.g., Holling and Meffe 1996), not initially considered when intervention began. This highlights the need to account for trade-offs between benefits and harm of regime management (Fig. 2), a pervasive dilemma (e.g., Rodríguez et al. 2006). These trade-offs and systems dynamics may be additionally influenced by the openness and connectivity of the system (Allen et al. 2016). From our examples, coerced grassland regimes have the fewest unintended or externalized negative side-effects, because management is based on fire, which comprises part of a natural disturbance regime

Fig. 2. Schematic showing scenarios of benefit-harm trade-offs associated with coerced regime management. Managing for coerced grassland regimes has the highest benefit and least impact. Bipolar disorder, acidification, and intensively subsidized agriculture show that negative effects of system coercion can outweigh benefits. Such effects may be influenced by system openness, which my cause spatial contagion effects of coercive management (agriculture affecting adjacent ecosystems versus bipolar disorder and lake acidification in which treatment is contained within the system). Note: The examples are largely simplified and meant for comparison and demonstration of trade-offs in the context of coerced regimes.

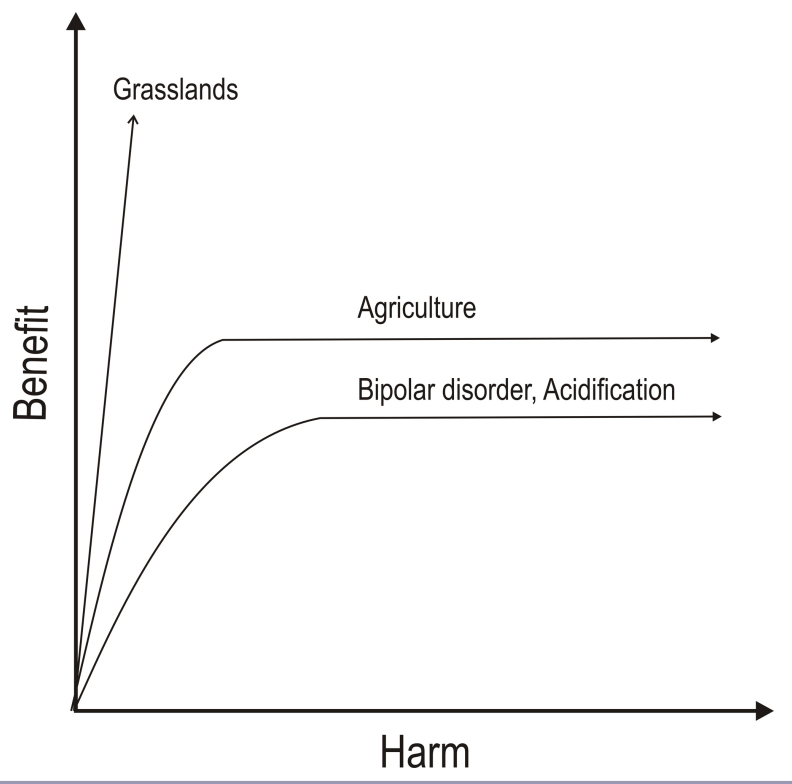


(DellaSala and Hanson 2015). In contrast, managing for the ghosts of desired regimes past in bipolar disorder and acidified lakes incurs more notable side-effects because the management subsidies are alien to the system. With psychopharmacological treatment in bipolar disorder, there is a substantial input of chemical drugs that do not occur naturally in the organism and that can cause, for instance, cardiovascular problems and other physical diseases (Correll et al. 2015). In acidified lakes, the input of lime not only causes a profound alteration in the biogeochemical structure of a lake but also leads to changes in algal body morphology (Drakare et al. 2012). Lakes and human subjects are complex-system types in which treatment, i.e., management, and associated side-effects are contained within the individual system. This differs from agricultural systems that are spatially open. As a result, negative effects of agriculture can be locally and regionally substantial and alter hydrological and ecological environments on account of intensive irrigation and the use of inputs, such as fertilizers and pesticides (Goudie 2018). In the case of climate regime management, which can be based on technological, cultural, economic, and social measures, the trade-offs between potential harms and benefits of Earth stewardship measures are again difficult to envision partly because of the scales and multidimensionality at which these measures interact with biophysical processes of the planet.

\section{OUTLOOK}

The degree of the amount of management needed to obtain desirable regimes exemplified by our example systems, which is inherent in the concept of coerced regimes, has fundamental implications for the sustainable management of complex systems of people and nature in a rapidly changing world. These implications become evident in two distinctly different management premises. The first premise relates to what we know about systems and the visions we have about managing these for the benefit of human societies, including nature and biodiversity conservation and ecosystem service provisioning. In the grassland example, management is geared toward conserving threatened and endangered wildlife species by maintaining habitat in a slowly, but fundamentally, shifting landscape. However, grassland conservation provides a striking example that envisioning successful species conservation based on knowledge about their habitat use becomes fallacious. This fallacy arises because management builds on assumptions that the dynamics of socialecological systems are stationary. That is, assuming that restoring habitats at small scales will bring the species back while habitat destruction and degradation proceed at broader scales - the myth of the field of dreams (Hilderbrand et al. 2005) - is bound to fail because a plethora of factors, including Allee effects, metapopulation and metacommunity dynamics, landscape change, habitat destruction and fragmentation, and spatial connectivity, cause an extinction debt that leads to the loss of species in the long run (Tilman et al. 1994). In other words, landscapes in which small-scale habitats are embedded are not static but shifting in response to environmental change and other disturbances, so management policies that focus on habitat restoration and assume all else is held constant are fundamentally flawed. Furthermore, the rate and magnitude of climate change amplifies both the inherent dynamism of landscapes and nonstationarity as a result of the human-driven disturbances listed above, which contributes to the creation of the ghosts of alternative regimes and eventually dead regimes walking (Craig 2010, Vitousek et al. 1997, Pecl et al. 2017). From this perspective, attempts to manage grassland regimes only "buy time" (Biggs et al. 2009) to conserve emblematic wildlife. We will eventually falter in our endeavor to save many species from extinctions. Nonstationarity shatters the field of dreams and will likely curtail management of desirable system conditions in the long term.

The inability of humans to manage complex-system regimes ad infinitum raises questions about the long-term costs and consequences associated with the buying of time, specifically, the trade-offs between benefit and harm that arise from management and the challenge to optimize the former and minimize the latter. This brings us to the second management premise, which is based on nonstationary assumptions: what we do not know and therefore cannot envision. That is, instead of managing regimes for specific sets of commodities, transformations to alternative self-organizing regimes with novel sets of goods and services may become management alternatives or even priorities for future sustainability (Hobbs et al. 2009, Allen and Holling 2010). However, the implementation of this management premise is difficult. First, in addition to often being very costly, transformation is challenged by the difficulty or even impossibility of breaking the feedbacks of system regimes (Suding et al. 2004), to which, with exceptions (e.g., Herrmann et al. 2016), a significant number of failed restoration projects attest (e.g., Gulati et al. 2008, Palmer et al. 2010). This suggests that despite exhaustive adaptive experimentation and knowledge acquisition (Baho et al. 2017) we are unlikely to be sufficiently knowledgeable to intentionally create particular self-sustaining and desired novel system regimes. Given the reality of constant and increasingly faster nonstationary change, this management goal becomes even more unrealistic. As a result it is possible that the best we can do is manage for desirable regimes that require consistent management in the form of human-provided inputs to maintain feedbacks, even though these systems will have low resilience and unintended side-effects of management or social dynamics. Furthermore, transformations can only be carried out within specific bounds defined by the laws of nature. That is, deliberate conversion of one ecosystem type (e.g., a grassland) to another radically different one (coral reef) is practically impossible. As a result management will be needed to obtain coerced desirable regimes of complex systems that are otherwise untenable, but which may be brittle because of the influence of unintended side-effects of management or social dynamics. Second, for many systems we have neither the knowledge nor the vision of how a novel, future, viable, and self-organizing regime should look, although scenario planning, based on societal and technological factors, envisioned for instance in the current artificial intelligence debate (Tegmark 2017), may help for this purpose. A case in point is a future cure of human illness through nanotechnology presently envisioned in science fiction. Despite the appeal of this currently unrealistic scenario, and its delicate ethical implications, we currently lack knowledge and models for bioengineering humans into novel self-organizing regimes. For instance, we currently lack the science that would allow transforming mentally ill human subjects to a novel healthy regime. Third, as a global discourse on transformation grows steadily, the degree to which academic conceptions of the term (including inherent limitations) translate into the action arena of 
environmental and sustainable development will vary, highlighting complicated questions of who or what benefits from management and who or what is marginalized (Blythe et al. 2018). These are critically important questions to address as the need to manage systems for desired human outcomes increases.

In the face of these limitations, a sustainable future will, rather than depending on purposeful successful transformations into self-organizing, desirable regimes, likely require even further expanding degrees of management to satisfy the increasing needs of service provisioning for a growing human population. Several of our examples demonstrate that management can have substantial negative side-effects, and it is likely that increasing degrees of management of complex systems in the future will have detrimental long-term effects. System resilience that occurs largely as a result of human management is more fragile because of the lack of ecologically based, self-reinforcing feedbacks. For example, the condition of a medicated patient or limed lake is brittle, i.e. low resilience, which manifests in a fast return to diseased or acidified conditions once management is ceased. Exceeding the resilience of coerced regimes may lead to unforeseen surprises that manifest in a form of novel system structures that require even more intensive coercive management for mitigating negative impacts and providing commodities. Because managing for resilience is contingent on legal settings (Twidwell et al. 2019), substantial policy implications and challenges arise from such uncertainty. Events from the past, such as agriculture that led to regime shifts in lakes and required extensive management to mitigate cultural eutrophication (Carpenter 2005), may provide lessons for the future. Such lessons could form the cornerstone for envisioning and spurring thinking about the complexity associated with management for future sustainability, highlighting the broad utility of the concept of coerced regimes for theory and practice.

We conclude by highlighting that we have discussed the concept of coerced regimes from a point of view where management is mostly intentional. This is in line with a large body of research, which has shown that once humans are integrated into the system boundaries, the management becomes part of the regime feedbacks (Tavoni et al. 2012, Lade et al. 2015, Schlüter et al. 2014, 2019). We acknowledge that unintentional social dynamics may similarly result in coerced regimes. For example, the role of social flows such as migration and remittances can determine whether or not forest transitions occur (Ospina et al. 2019). Specifically, people migrate or send money to their families not with the intention of changing the forest, but forest changes are unintended consequences of such social dynamics. These examples make clear that the outcomes of intentional and unintentional human activity can have similar outcomes on ecosystem dynamics. Because both comprise some forms of human agency, the concept of coerced regimes is inclusive of such different forms. The concept therefore has the potential to spur the development of a research agenda to address ghost regimes in the Anthropocene: How does one identify them? How does one classify them? Are there archetypical configurations of ghost regimes? These questions need to revolve around our understanding of social dynamics as part of the feedbacks of the system. Actors actions, influences, and results (i.e., power dynamics), unintentional social dynamics (e.g., migration, remittances), and unintended side-effects of intentional management on ecosystems will play an important role in answering these questions.

Responses to this article can be read online at: http://www.ecologyandsociety.org/issues/responses. php/11286

\section{Acknowledgments:}

This work was conceived and carried out during a visiting professorship of DGA at the University of Nebraska-Lincoln. Any use of trade, firm, or product names is for descriptive purposes only and does not imply endorsement by the U.S. Government. The Nebraska Cooperative Fish and Wildlife Research Unit is jointly supported by a cooperative agreement among the U.S. Geological Survey, the Nebraska Game and Parks Commission, the University of Nebraska, the U.S. Fish and Wildlife Service, and the Wildlife Management Institute. The findings and conclusions in this manuscript are supported by the U.S. Geological Survey but have not been formally disseminated by the U.S. Environmental Protection Agency and should not be construed to represent this agency's determination or policy. The authors thank Dr. Elizabeth King and anonymous reviewers for helpful comments on a previous manuscript version.

\section{LITERATURE CITED}

Allen, C. R., D. G. Angeler, G. S. Cumming, C. Folke, D. Twidwell, and D. R. Uden. 2016. Quantifying spatial resilience. Journal of Applied Ecology 53:625-635. https://doi.org/10.1111/1365-2664.12634

Allen, C. R., D. G. Angeler, A. S. Garmestani, L. H. Gunderson, and C. S. Holling. 2014. Panarchy: theory and applications. Ecosystems 17:578-589. https://doi.org/10.1007/s10021-013-9744-2

Allen, C. R., and C. S. Holling. 2010. Novelty, adaptive capacity, and resilience. Ecology and Society 15(3):24. https://doi. org/10.5751/ES-03720-150324

Altieri, M. A., C. I. Nicholls, A. Henao, and M. A. Lana. 2015. Agroecology and the design of climate change-resilient farming systems. Agronomy for Sustainable Development 35:869-890. https://doi.org/10.1007/s13593-015-0285-2

Anderson, S. 2017. Coercion. The Stanford Encyclopedia of Philosophy. E. N. Zalta, editor. Stanford University, Stanford, California, USA. [online] URL: https://plato.stanford.edu/ archives/win2017/entries/coercion/

Angeler, D. G., and C. R. Allen. 2016. Quantifying resilience. Journal of Applied Ecology 53:617-624. https://doi. org/10.1111/1365-2664.12649

Angeler, D. G., C. R. Allen, C. Barichievy, T. Eason, A. S. Garmestani, N. A. J. Graham, D. Granholm, L. H. Gunderson, M. Knutson, K. L. Nash, R. J. Nelson, M. Nyström, T. L. Spanbauer, C. A. Stow, and S. M. Sundstrom. 2016. Management applications of discontinuity theory. Journal of Applied Ecology 53:688-698. https://doi.org/10.1111/1365-2664.12494 
Angeler, D. G., C. R. Allen, and M.-L. Persson. 2018. Resilience concepts in psychiatry demonstrated with bipolar disorder. International Journal of Bipolar Disorders 6:2. https://doi. org/10.1186/s40345-017-0112-6

Angeler, D. G., S. Drakare, R. K. Johnson, S. Köhler, and T. Vrede. 2017. Managing ecosystems without prior knowledge: pathological outcomes of lake liming. Ecology and Society 22 (4):44. https://doi.org/10.5751/ES-09794-220444

Angeler, D. G., H. B. Fried-Petersen, C. R. Allen, A. Garmestani, D. Twidwell, W.-C. Chuang, V. M. Donovan, T. Eason, C. P. Roberts, S. M. Sundstrom, and C. L. Wonkka. 2019. Adaptive capacity in ecosystems. Advances in Ecological Research 60:1-24. https://doi.org/10.1016/bs.aecr.2019.02.001

Archer, S. R., and K. I. Predick. 2014. An ecosystem services perspective on brush management: research priorities for competing land-use objectives. Journal of Ecology 102:1394-1407. https://doi.org/10.1111/1365-2745.12314

Baho, D. L., C. R. Allen, A. S. Garmestani, H. B. Fried-Petersen, S. E. Renes, L. Gunderson, and D. G. Angeler. 2017. A quantitative framework for assessing ecological resilience. Ecology and Society 22(3):17. https://doi.org/10.5751/ES-09427-220317

Baho, D. L., S. Drakare, R. K. Johnson, C. R. Allen, and D. G. Angeler. 2014. Similar resilience attributes in lakes with different management practices. PLOS ONE 9(3):e91881. https://doi. org/10.1371/journal.pone.0091881

Bauer, M., and A. Pfennig. 2005. Epidemiology of bipolar disorders. Epilepsia 46:8-13. https://doi.org/10.1111/

j.1528-1167.2005.463003.x

Beaugrand, G., A. Conversi, S. Chiba, M. Edwards, S. FondaUmani, C. Greene, N. Mantua, S. A. Otta, P. C. Reid, M. M. Stachura, L. Stemmann, and H. Sugisaki. 2015. Synchronous marine pelagic regime shifts in the Northern Hemisphere. Philosophical Transactions of the Royal Society B 370 (1659):20130272. https://doi.org/10.1098/rstb.2013.0272

Beisner, B. E., D. T. Haydon, and K. Cuddington. 2003. Alternative stable states in ecology. Frontiers in Ecology and the Environment 1:376-382. https://doi.org/10.1890/1540-9295(2003) 001[0376:ASSIE]2.0.CO;2

Biggs, R., S. R. Carpenter, and W. A. Brock. 2009. Turning back from the brink: detecting an impending regime shift in time to avert it. Proceedings of the National Academy of Sciences 106:826-831. https://doi.org/10.1073/pnas.0811729106

Biggs, R., G. D. Peterson, and J. C. Rocha. 2018. The regime shifts database: a framework for analyzing regime shifts in socialecological systems. Ecology and Society 23(3):9. https://doi. org/10.5751/ES-10264-230309

Blythe, J., J. Silver, L. Evans, D. Armitage, N. J. Bennett, M.-L. Moore, T. H. Morrison, and K. Brown. 2018. The dark side of transformation: latent risks in contemporary sustainability discourse. Antipode 50:1206-1223. https://doi.org/10.1111/ $\underline{\text { anti. } 12405}$

Briggs, J. M., A. K. Knapp, J. M. Blair, J. L. Heisler, G. A. Hoch, M. S. Lett, and J. K. McCarron. 2005. An ecosystem in transition: causes and consequences of the conversion of mesic grassland to shrubland. Bioscience 55:243-254. https://doi.org/10.1641/0006-3568 (2005)055[0243:AEITCA]2.0.CO;2

Carpenter, S. R. 2005. Eutrophication of aquatic ecosystems: bistability and soil phosphorus. Proceedings of the National Academy of Sciences 102:10002-10005. https://doi.org/10.1073/ pnas.0503959102

Carpenter, S. R., W. A. Brock, G. J. A. Hansen, J. F. Hansen, J. M. Hennessy, D. A. Isermann, E. J. Pedersen, K. M. Perales, A. L. Rypel, G. G. Sass, T. D. Tunney, and M. J. Vander Zanden. 2017. Defining a safe operating space for inland recreational fisheries. Fish and Fisheries 18:1150-1160. https://doi.org/10.1111/ $\underline{\text { faf. } 12230}$

Cassey, P., S. Delean, J. L. Lockwood, J. S. Sadowski, and T. M. Blackburn. 2018. Dissecting the null model for biological invasions: a meta-analysis of the propagule pressure effect. PLoS Biology 16(4):e2005987 https://doi.org/10.1371/journal.pbio. 2005987

Clair, T. A., and A. Hindar. 2005. Liming for the mitigation of acid rain effects in freshwaters: a review of recent results. Environmental Reviews 13:91-128. https://doi.org/10.1139/ a05-009

Cooke, G. D. 1999. Ecosystem rehabilitation. Lake and Reservoir Management 15(1):1-4.

Correll, C. U., J. Detraux, J. De Lepeleire, and M. De Hert. 2015. Effects of antipsychotics, antidepressants and mood stabilizers on risk for physical diseases in people with schizophrenia, depression and bipolar disorder. World Psychiatry 14(2):119-136. https://doi.org/10.1002/wps.20204

Craig, R. K. 2010. Stationarity is dead-long live transformation: five principles for climate change adaptation law. Harvard Environmental Law Review 34:9.

DellaSala, D. A., and C. T. Hanson. 2015. The ecological importance of mixed-severity fires: nature's phoenix. Elsevier, Amsterdam, The Netherlands.

Drakare, S., G. Persson, D. Angeler, and K. Holmgren. 2012. IKEUs Överkalkningsprogram, 2006-2010: Vilka effekter på biota ser man I överkalkade sjöar. Institutionen för vatten och miljö, Sveriges lantbruksuniversitet, Uppsala, Sweden.

Ferrell Jr, J. E. 2002. Self-perpetuating states in signal transduction: positive feedback, double-negative feedback and bistability. Current Opinion in Cell Biology 14:140-148. https://doi. org/10.1016/S0955-0674(02)00314-9

Figura, S., D. M. Livingstone, E. Hoehn, and R. Kipfer. 2011. Regime shift in groundwater temperature triggered by the Arctic Oscillation. Geophysical Research Letters 38:1-5 https://doi. org/10.1029/2011g1049749

Fuhlendorf, S. D., C. A. Davis, R. D. Elmore, L. E. Goodman, and R. G. Hamilton. 2018. Perspectives on grassland conservation efforts: should we rewild to the past or conserve for the future? Philosophical Transactions of the Royal Society B 373 (1761):20170438. https://doi.org/10.1098/rstb.2017.0438

Garibaldi, L. A., B. Gemmill-Herren, R. D'Annolfo, B. E. Graeub, S. A. Cunningham, and T. D. Breeze. 2017. Farming approaches for greater biodiversity, livelihoods, and food security. 
Trends in Ecology \& Evolution 32:68-80. https://doi.org/10.1016/ j.tree.2016.10.001

Gill, D. S., and P. L. Marks. 1991. Tree and shrub seedling colonization of old fields in central New York. Ecological Monographs 61:183-205. https://doi.org/10.2307/1943007

Goodwin, F. K., and K. R. Jamison. 2007. Manic-depressive illness: bipolar disorders and recurrent depression. Oxford University Press, New York, New York, USA.

Gordon, L. J., G. D. Peterson, and E. M. Bennett. 2008. Agricultural modifications of hydrological flows create ecological surprises. Trends in Ecology \& Evolution 23:211-219. https://doi. org/10.1016/j.tree.2007.11.011

Goudie, A. S. 2018. Human impact on the natural environment. John Wiley \& Sons, Hoboken, New Jersey, USA.

Grant, T. A., E. Madden, and G. B. Berkey. 2004. Tree and shrub invasion in northern mixed-grass prairie: implications for breeding grassland birds. Wildlife Society Bulletin 32:807-818. https://doi.org/10.2193/0091-7648(2004)032[0807:TASIIN]2.0.CO;2

Gulati, R. D., L. M. D. Pires, and E. Van Donk. 2008. Lake restoration studies: failures, bottlenecks and prospects of new ecotechnological measures. Limnologica 38:233-247. https://doi. org/10.1016/j.limno.2008.05.008

Gunderson, L. H. 2000. Ecological resilience-in theory and application. Annual Review of Ecology and Systematics 31:425-439. https://doi.org/10.1146/annurev.ecolsys.31.1.425

Handy, J. A. 2018. The secret tribe: a memoir of resilience. Friesen, Victoria, British Columbia, Canada.

Henriksson, L., and Y. N. Brodin. 1995. Liming of acidified surface waters: a Swedish synthesis. Springer, Berlin, Germany.

Herrmann, D. L., K. Schwarz, W. D. Shuster, A. Berland, B. C. Chaffin, A. S. Garmestani, M. E. Hopton. 2016. Ecology for the shrinking city. BioScience 66:965-973. https://doi.org/10.1093/ biosci/biw062

Hilderbrand, R. H., A. C. Watts, and A. M. Randle. 2005. The myths of restoration ecology. Ecology and Society 10(1):19 https:// doi.org/10.5751/ES-01277-100119

Hobbs, R. J., E. Higgs, and J. A. Harris. 2009. Novel ecosystems: implications for conservation and restoration. Trends in Ecology \& Evolution 24:599-605. https://doi.org/10.1016/j.tree.2009.05.012

Holland, J. H. 2014. Complexity: a very short introduction. Oxford University Press, Oxford, UK.

Holling, C. S. 1973. Resilience and stability of ecological systems. Annual Review of Ecology and Systematics 4(1):1-23. https://doi. org/10.1146/annurev.es.04.110173.000245

Holling, C. S. 2001. Understanding the complexity of economic, ecological, and social systems. Ecosystems 4:390-405. https://doi. org/10.1007/s10021-001-0101-5

Holling, C. S., and G. K. Meffe. 1996. Command and control and the pathology of natural resource management. Conservation Biology 10:328-337. https://doi.org/10.1046/j.1523-1739.1996.10020328. $\underline{\mathrm{x}}$
Intergovernmental Panel on Climate Change (IPCC). 2014. Climate change 2014: synthesis report. Contribution of Working Groups I, II and III to the Fifth Assessment Report of the Intergovernmental Panel on Climate Change. Core Writing Team, R. K. Pachauri, and L.A. Meyer, editors. IPCC, Geneva, Switzerland.

Koohafkan, P., M. A. Altieri, and E. H. Gimenez. 2012. Green agriculture: foundations for biodiverse, resilient and productive agricultural systems. International Journal of Agricultural Sustainability 10:61-75. https://doi.org/10.1080/14735903.2011.610206

Kortsch, S., R. Primicerio, F. Beuchel, P. E. Renaud, J. Rodrigues, O. J. Lønne, and B. Gulliksen. 2012. Climate-driven regime shifts in Arctic marine benthos. Proceedings of the National Academy of Sciences 109:14052-14057. https://doi.org/10.1073/pnas.1207509109

Lade, S. J., S. Niiranen, J. Hentati-Sundberg, T. Blenckner, W. J. Boonstra, K. Orach, M. F. Quaas, H. Österblom, and M. Schlüter. 2015. An empirical model of the Baltic Sea reveals the importance of social dynamics for ecological regime shifts. Proceedings of the National Academy of Sciences 112:11120-11125. https://doi. org/10.1073/pnas.1504954112

Lustgarten, A., and N. Sadasivam. 2015. Holy crop: how federal dollars are financing the water crisis in the West. ProPublica, 27 May. [online] URL: https://projects.propublica.org/killing-thecolorado/story/arizona-cotton-drought-crisis

Milkowitz, D. J., and M. J. Gitlin. 2015. Clinician's guide to bipolar disorder. Guilford, New York, New York, USA.

Miller, M. H., and J. Williamson. 1988. The international monetary system: an analysis of alternative regimes. European Economic Review 32:1031-1048

Ospina, D., G. Peterson, and A. S. Crépin. 2019. Migrant remittances can reduce the potential of local forest transitions: a social-ecological regime shift analysis. Environmental Research Letters 14:024017. https://doi.org/10.1088/1748-9326/aaf0ee

Palmer, M. A., H. L. Menninger, and E. Bernhardt. 2010. River restoration, habitat heterogeneity and biodiversity: a failure of theory or practice? Freshwater Biology 55:205-222. https://doi. org/10.1111/j.1365-2427.2009.02372.x

Pecl, G. T., M. B. Araújo, J. D. Bell, J. Blanchard, T. C. Bonebrake, I.-C. Chen, T. D. Clark, R. K. Cowell, F. Danielsen, B. Evengård, et al. 2017. Biodiversity redistribution under climate change: impacts on ecosystems and human well-being. Science 355: eaai9214. https://doi.org/10.1126/science.aai9214

Phelps, J. 2006. Why am I still depressed? Recognizing and managing the ups and downs of Bipolar II and soft bipolar disorder. McGraw-Hill, New York, New York, USA.

Rist, L., A. Felton, M. Nyström, M. Troell, R. A. Sponseller, J. Bengtsson, H. Österblom, R. Lindborg, P. Tidåker, D. G. Angeler, R. Milestad, and J. Moen. 2014. Applying resilience thinking to production ecosystems. Ecosphere 5(6):1-11. https://doi. org/10.1890/ES13-00330.1

Roberts, C. P., C. R. Allen, D. G. Angeler, and D. Twidwell. 2019. Shifting avian spatial regimes in a changing climate. Nature Climate Change 9:562-566. https://doi.org/10.1038/s41558-019-0517-6 
Rockström, J., W. Steffen, K. Noone, Å. Persson, F. S. Chapin, III, E. Lambin, T. M. Lenton, M. Scheffer, C. Folke, H. Schellnhuber, B. Nykvist, C. A. De Wit, T. Hughes, S. van der Leeuw, H. Rodhe, S. Sörlin, P. K. Snyder, R. Costanza, U. Svedin, M. Falkenmark, L. Karlberg, R. W. Corell, V. J. Fabry, J. Hansen, B. Walker, D. Liverman, K. Richardson, P. Crutzen, and J. Foley. 2009. Planetary boundaries: exploring the safe operating space for humanity. Ecology and Society 14(2):32. https://doi. org/10.5751/ES-03180-140232

Rodríguez, J. P., T. D. Beard, Jr., E. M. Bennett, G. S. Cumming, S. Cork, J. Agard, A. P. Dobson, and G. D. Peterson. 2006. Tradeoffs across space, time, and ecosystem services. Ecology and Society 11(1):28. https://doi.org/10.5751/ES-01667-110128

Samson, F., and F. Knopf. 1994. Prairie conservation in North America. Bioscience 44:418-421. https://doi.org/10.2307/1312365

Sandøy, S., and A. J. Romunstad. 1995. Liming of acidified lakes and rivers in Norway: an attempt to preserve and restore biological diversity in the acidified regions. Water, Air, and Soil Pollution 85:997-1002. https://doi.org/10.1007/BF00476960

Scheffer, M., S. H. Hosper, M.-L. Meijer, B. Moss, and E. Jeppesen. 1993. Alternative equilibria in shallow lakes. Trends in Ecology \& Evolution 8:275-279. https://doi.org/10.1016/0169-5347 (93)90254-M

Schindler, D. W. 1988. Effects of acid rain on freshwater ecosystems. Science 239:149-157. https://doi.org/10.1126/ science.239.4836.149

Schlüter, M., L. Haider, S. J. Lade, E. Lindkvist, R. Martin, K. Orach, N. Wijermans, and C. Folke. 2019. Capturing emergent phenomena in social-ecological systems: an analytical framework. Ecology and Society 24(3):11. https://doi. org/10.5751/es-11012-240311

Schlüter, M., J. Hinkel, P. W. G. Bots, and R. Arlinghaus. 2014. Application of the SES framework for model-based analysis of the dynamics of social-ecological systems. Ecology and Society 19(1):36. https://doi.org/10.5751/ES-05782-190136

Society for Ecological Restoration (SER). 2004. The SER International Primer on Ecological Restoration. SER, Washington, D.C., USA.

Steffen, W., J. Rockström, K. Richardson, T. M. Lenton, C. Folke, D. Liverman, C. P. Summerhayes, A. D. Barnosky, S. E. Cornell, M. Crucifix, et al. 2018. Trajectories of the Earth System in the Anthropocene. Proceedings of the National Academy of Sciences 115:8252-8259. https://doi.org/10.1073/pnas.1810141115

Stockholm Resilience Center. 2014. The hidden cost of coerced resilience. Stockholm Resilience Center, Stockholm University, Stockholm, Sweden. [online] URL: http://www.stockholmresilience. org/research/research-news/2014-11-29-the-hidden-cost-of-coercedresilience.html

Suding, K. N., and K. L. Gross. 2006. The dynamic nature of ecological systems: multiple states and restoration trajectories. Pages 190-209 in D. A. Falk, M. A., Palmer, and J. B. Zedler, editors. Foundations of restoration ecology. Island, Washington, D.C., USA.
Suding, K. N., K. L. Gross, and G. R. Houseman. 2004. Alternative states and positive feedbacks in restoration ecology. Trends in Ecology \& Evolution 19:46-53. https://doi.org/10.1016/ j.tree.2003.10.005

Suding, K. N., and R. J. Hobbs. 2009. Threshold models in restoration and conservation: a developing framework. Trends in Ecology and Evolution 24:271-279. https://doi.org/10.1016/j. tree.2008.11.012

Tavoni, A., M. Schlüter, and S. Levin. 2012. The survival of the conformist: social pressure and renewable resource management. Journal of Theoretical Biology 299:152-161. https://doi. org/10.1016/j.jtbi.2011.07.003

Tegmark, M. 2017. Life 3.0 - Being human in the age of artificial intelligence. Alfred A. Knopf, New York, New York, USA.

Tilman, D., R. M. May, C. L. Lehman, and M. A. Nowak. 1994. Habitat destruction and the extinction debt. Nature 371:65-66. https://doi.org/10.1038/371065a0

Twidwell, D., C. L. Wonkka, H.-H. Wang, W. E. Grant, C. R. Allen, S. D. Fuhlendorf, A. S. Garmestani, D. G. Angeler, C. A. Taylor Jr, U. P Kreuter, and W. E. Rogers. 2019. Coerced resilience in fire management. Journal of Environmental Management 240:368-373. https://doi.org/10.1016/j.jenvman.2019.02.073

Vitousek, P. M., H. A. Mooney, J. Lubchenco, and J. M. Melillo. 1997. Human domination of Earth's ecosystems. Science 277:494-499. https://doi.org/10.1126/science.277.5325.494

Wandelt, K. 2018. Encyclopedia of interfacial chemistry: surface science and electrochemistry. Elsevier, Amsterdam, The Netherlands.

Westerling, A. L., H. G. Hidalgo, D. R. Cayan, and T. W. Swetnam. 2006. Warming and earlier spring increase western U. S. forest wildfire activity. Science 313:940-943. https://doi. org/10.1126/science. 1128834 